\title{
ANÁLISE COMPARATIVA DOS CUSTOS DE PRODUÇÃO ENTRE UMA VARIEDADE DE SOJA NÃO TRANSGÊNICA E UMA VARIEDADE TRANSGÊNICA EM TOLEDO - PARANÁ
}

\section{A COMPARATIVE ANALYSIS OF PRODUCTION COSTS BETWEEN NON TRANSGENICS SOYBEANS AND TRANGENICS SOYBEANS IN TOLEDO - PARANÁ}

\author{
Glauber Aldrei Rinaldi ${ }^{1}$; Eduardo César Dechechi ${ }^{2}$; José Cardoso Sobrinho ${ }^{3}$ \\ ${ }^{1}$ Graduando em Engenharia de Produção Agroindustrial na Pontifícia Universidade Católica \\ do Paraná - PUC-PR, Campus Toledo - Paraná, glauber.rinaldi@pucpr.br \\ ${ }^{2}$ Pós-Doutor em Engenharia Química - Universidade Estadual de Campinas - UNICAMP \\ - Campinas - São Paulo, Coordenador do curso de Engenharia de Produção \\ Agroindustrial da Pontifícia Universidade Católica do Paraná - PUC-PR, Campus Toledo, \\ eduardo.dechechi@pucpr.br \\ ${ }^{3}$ Doutor em Engenharia Agrícola - Universidade Federal de Viçosa - Viçosa - Minas Gerais. \\ Professor Adjunto do curso de Engenharia de Produção Agroindustrial da Pontifícia \\ Universidade Católica do Paraná - PUC-PR / Campus Toledo, jose.sobrinho@pucpr.br
}

Recebido para publicação em: 11/04/2005

Aceito para publicação em: 19/08/2005

\section{Resumo}

Para enfrentar com eficiência a competitividade que caracteriza o complexo soja, é indispensável o uso de tecnologia desde a produção primária. O uso de variedades transgênicas no cultivo da soja, reduz o número e o custo das aplicações de defensivos. Assim, este estudo objetiva comparar os custos de produção entre uma variedade de soja não transgênica e uma variedade transgênica, na cidade de Toledo,

Estado do Paraná, na safra de 2003/2004.

Palavras-chave: Soja, Transgênicos, Custos de Produção

\section{Introdução}

A cultura da soja (Glicine max (L.) Merrill) transformou-se na principal cultura brasileira em área cultivada, elevando o Brasil à condição de segundo maior produtor mundial e primeiro país exportador, sendo que desde a entrada do novo século o plantio de grãos aumentou rapidamente, e a área ocupada já avançou 10 mil hectares, representando um aumento de $30 \%$ em relação à área de plantio do ano 2000. (ROESSING, 2004). 
Entretanto, apesar deste complexo apresentar um mercado mundial crescente, para que a soja possa enfrentar com eficiência a grande competitividade que caracteriza o mercado, é importante que esta cultura seja protegida contra a invasão de plantas daninhas agressivas.

De acordo com Ruedell (2003), a soja não pode competir nos estágios iniciais da produção, sendo protegida contra a invasão de plantas daninhas agressivas. Os sistemas de manejo atuais mesclam práticas culturais e mecânicas com herbicidas, para superar o efeito competitivo.

A introdução da soja transgênica reduz o número e o custo das aplicações de herbicidas, resultando em controle igual, ou melhor, das plantas daninhas. Nesse sentido, o presente trabalho objetiva apresentar um comparativo dos custos de produção entre a Soja Não-Transgênica e a Soja Transgênica da variedade Roundup Ready, ou seja resistente ao herbicida Glifosato, no município de Toledo, estado do Paraná, na safra de 2003/2004 .

Para tanto, será utilizada metodologia específica, buscando proceder a análise dos aspectos que envolvem a cultura da soja. Observa-se ainda que este trabalho encontra-se dividido em 4 seções. Na primeira seção, é realizada a introdução que apresenta alguns dados sobre o complexo soja. Na segunda seção são apresentadas as considerações teóricas sobre a importância sócioeconômica da cultura da soja, a biotecnologia e os trangênicos, sobre a linhagem _ Roundup Ready_, a noção de royalties e a descrição dos elementos utilizados para mensurar os custos de produção. A terceira seção apresenta os resultados da pesquisa e, por fim, a quarta seção expõe as conclusões sobre os resultados encontrados na pesquisa.

\section{Revisão teórica}

\subsection{Importância sócio-econômica}

A soja é hoje o principal produto de exportação do Brasil, sendo de grande importância para a economia brasileira pela entrada de importantes divisas, contribuindo decisivamente com a balança brasileira de pagamentos. (ROESSING,2004)

Ainda de acordo com ROESSING (2004), o ranking mundial de produção aponta os EUA como o maior produtor, tendo colhido na safra de 2003/04 um volume de 65.796 mil toneladas, seguido pelo Brasil, que a cada ano, devido a sua potencialidade de aumento da área de plantio (grandes áreas de pastagens degradadas são recuperadas através do uso de tecnologias), tem como reflexo direto um aumento na sua produção, cuja safra de 2003/04 foi de 50.188 mil Toneladas. 


\subsection{Biotecnologia e transgênicos}

A busca, através de cruzamento, de novas variedades vegetais a fim de obter plantas mais produtivas ou resistentes a pragas é prática antiga e habitual na agricultura de todas as sociedades. As técnicas modernas de engenharia genética permitem que se retirem genes de um organismo e se transfiram para outro. Esses genes "estrangeiros" quebram a seqüência de DNA - que contém as características de um ser vivido organismo receptor, que sofre uma espécie de reprogramação, tornando-se capaz de produzir novas substâncias. Esses são os chamados transgênicos, ou organismos geneticamente modificados (OGMs).

Conforme Barnes (2002), variedades geneticamente modificadas de milho e soja vem sendo cultivadas em maior escala nos Estados Unidos, Canadá e China, incluindo modificações que conferem tolerância a herbicidas, resistência a insetos ou ambas as características. Atualmente, cerca de $80-90 \%$ da produção mundial de óleo de soja provem de cultura de soja geneticamente modificada, por apresentar como principal vantagem o menor uso de herbicida. O setor alimentício europeu, entretanto, não é detentor desta tecnologia em escala comercial e produz pequena parcela de alimentos geneticamente modificados, tendo como principal produto agrícola modificado o milho, que é cultivado na Espanha e França.

A regulamentação da biotecnologia foi pela primeira vez considerada em 1970 quando solicitou-se moratória para aplicação desta tecnologia até que estudos relacionados à Biossegurança fossem realizados. A partir desta época vários regulamentos foram estabelecidos pelos diferentes países, visando o controle do uso desta tecnologia, considerando os aspectos de segurança para o homem, animais e para o meio ambiente.(Leite, 2000) Na Europa, duas Diretivas (219/90 e 220/90 com revisão proposta pelo Parlamento Inglês em Fevereiro de 1998) estabelecem respectivamente procedimentos para o trabalho em contenção e para a liberação controlada no meio ambiente de Organismos Geneticamente Modificados. (Barnes, 2002)

Os Estados Unidos são os maiores detentores das aplicações comerciais da moderna biotecnologia com uma área de 27,8 milhões de hectares de cultivos de produtos geneticamente modificados em 1998, dos quais 71\% representam culturas modificadas para a característica de tolerância a herbicida. Os Estados Unidos também são o maior exportador de culturas geneticamente modificadas, e vem regulando a biotecnologia de forma distinta do modelo regulatório adotado pela Europa. O Governo Americano considera as novas técnicas de modificação genética como uma extensão dos demais processos tecnológicos, vendo os novos produtos desenvolvidos por esta técnica como análogos aos já existentes, no que diz respeito aos procedimentos de avaliação de segurança. (Gazzoni, 2002). 
Existe hoje uma série de projetos de pesquisa na área para desenvolvimento de produtos com novas características, seja de resistência a herbicidas, doenças ou fatores bióticos, como também maior valor nutricional ou farmacêutico. Podem ser citados como exemplos destes novos produtos o mamão resistente ao vírus da mancha anelar, o feijão resistente ao vírus do mosaico dourado, o algodão resistente ao bicudo, a soja tolerante à seca, o milho resistente a solos com elevado teor de alumínio, o milho com elevado teor de metionina ou para produção do hormônio do crescimento, entre outros.

Todas essas pesquisas, para serem realizadas, devem observar uma série de normas estabelecidas pela legislação brasileira de biossegurança. A principal norma vigente neste aspecto é a Lei $n^{\circ}$ 8.974/95 (Lei de Biossegurança) alterada pela Medida Provisória $n^{\circ}$ 2.191-9/2001, e seu decreto regulamentador (Decreto $\left.\mathrm{n}^{\mathrm{o}} 1.752 / 95\right)$.

Tais normas criaram a Comissão Técnica Nacional de Biossegurança (CTNBio), que editou, de 1996 até 2002, 20 instruções normativas que regulamenta a matéria. Além disso, também tem interface com a questão a legislação ambiental, em especial, o disposto na Lei ${ }^{\circ}$ 6.938/81 e no Anexo da Lei $n^{\circ} 10.165 / 2000$. Para regulamentar a matéria do ponto de vista ambiental, foi editada a Resolução no 305/2002 do Conselho Nacional do Meio Ambiente - CONAMA, além de Instruções Normativas específicas do Instituto Brasileiro do Meio Ambiente e Recursos Renováveis - IBAMA.

Outra legislação que apresenta interface com a de biossegurança é a de Agrotóxicos, em especial a Lei $n^{\circ} 7.802 / 89$ e o Decreto $n^{\circ} 4.074 / 2002$. No caso específico dos organismos geneticamente modificados (OGMs), sendo que existem três normas que regulam a concessão do Registro Especial Temporário: a Instrução Normativa Conjunta $\mathrm{n}^{\mathrm{o}}$ 02/2002 do MAPA/ANVISA/IBAMA, a Instrução Normativa n 24/2002 do Ibama e a Resolução no 57/2002 da IBAMA. Além destas normas, existe ainda o Decreto $n^{\circ} 4.680 / 2003$, que regula a questão da rotulagem de produtos que contêm organismos geneticamente modificados ou derivados em sua composição e as Leis $n^{0} 10.688 / 2003$ e $n^{0} 10.814 / 2003$, que tratam da questão do plantio e da comercialização de soja transgênica no País, nas safras 2002/2003 e 2003/2004.

A FAO (Organização para as nações unidas para alimentação) considera biossegurança a correlação do uso sadio e sustentável do meio ambiente, dos produtos biotecnológicos e as interrecorrências para a saúde da população: biodiversidade e sustentabilidade ambiental, com vistas à segurança alimentar global (NODARI e GUERRA, 2000).

Binsfeld (2000) ressalta que é necessário que todos os produtos transgênicos sejam examinados, avaliados e julgados, caso a caso, tendo em vista a sua finalidade benéfica e que, em concordância com a legislação e baseados nos preceitos éticos, morais, sócio-econômicos e de 
segurança ambiental, venham garantir vantagens ao consumidor e ao processo produtivo, sem que, no entanto, se ponha em risco à vida e sua evolução.

No Brasil, o processo que garante a segurança e a qualidade dos alimentos, por parte do governo, das unidades de produção agropecuária, das indústrias e dos distribuidores, e também dos consumidores, enfrenta dificuldades. As políticas públicas estão cada vez mais orientadas para a descentralização estadual e municipal. A população que exerce e exige o controle de segurança de qualidade dos alimentos, ainda é um contingente pequeno (CAVALLI, 2001).

\subsubsection{Soja transgênica - ROUNDUP READY}

Com relação à soja transgênica, a linhagem em questão é a GTS 40-30-2, mais conhecida como Roundup Ready, ou soja RR. A soja RR foi obtida a partir da inserção de três genes "estrangeiros" na planta da soja. Um deles foi extraído de um vírus e um outro de uma bactéria encontrada no solo, a Agrobacterium sp. O gene, denominado CP4 EPSPS, proveniente do microorganismo Agrobacterium sp. estirpe CP4, codifica a enzima 5-enolpirovinil-chiquimato-3fosfato sintase (EPSPS), a qual participa da reação de síntese de aminoácidos aromáticos (fenilalanina, tirosina e triptofano). O DNA exógeno foi inserido no tecido meristemático da planta da cultivar de soja A5403, através do método de transformação de plantas por aceleração ou bombardeamento de partículas. A proteína é expressa em todos os órgãos da planta, sendo que essa modificação genética não incrementa a produtividade da cultura, ou o valor nutricional do grão. $\mathrm{O}$ efeito conhecido desse gene, alegado como economicamente vantajoso, consiste em possibilitar a substituição de vários herbicidas por apenas um, que contenha como ingrediente ativo o glifosato.(MELGAREJO,2002)

Plantas tolerantes ao herbicida glifosato têm sido cultivadas em escala comercial desde 1996 nos Estados Unidos e desde 1997 na Argentina. No Brasil, em 24 de setembro de 1998, apesar de uma liminar que sustava o plantio, obtida pelo Instituto Brasileiro de Defesa do Consumidor (IDEC) e pela organização ambientalista Greenpeace, a CTNBio reiterou sua autorização, deliberando que nada haveria a temer do ponto de vista da biossegurança e deixando outros aspectos de licenciamento a critério do Ministério da Agricultura. Era a primeira licença que a Comissão concedia para cultivo em escala comercial, mas já haviam sido aprovadas dezenas de outras licenças para testes experimentais, normalmente realizados em áreas diminutas (da ordem de uns poucos hectares cada uma) e submetidos a severas medidas de segurança, para evitar dispersão de pólen e a queima de todos os pés da leguminosa após a colheita. (ANBio,2001).

Ainda, em 1998, a liberação do cultivo da soja transgênica teve no Rio Grande do Sul o apogeu de recursos e liminares, objetivando impedir o cultivo das sementes da soja transgênica. 
Independente das ações judiciais constituídas, o Rio Grande do Sul foi a região do Brasil onde mais se plantou soja transgênica resistente ao glifosato, com recurso de sementes ilegalmente importadas da Argentina.

\subsubsection{Royalties - Soja RR}

A noção de royalties, ou regalias, é construída na legislação tributária interna pelo art. 22 da Lei 4.506/64. Segundo a lei, são royalties:

\footnotetext{
"Os rendimentos de qualquer espécie decorrentes do uso, fruição ou exploração de direitos, tais como: a) direitos de colher ou extrair recursos vegetais, inclusive florestais; b) direito de pesquisar e extrair recursos minerais; c) uso ou exploração de invenções, processos e fórmulas de fabricação e de marcas de indústria e comércio; d) exploração de direitos autorais, salvo quando percebidos pelo autor ou criador do bem ou obra". (art.22 da Lei $4.506 / 64)$
}

De acordo com Loureiro (2003), o processo biotecnológico de transferência do gen RR para a soja foi patenteado pela multinacional Monsanto (Lei de Patentes). A Monsanto incorporou o gen RR em cultivares da Embrapa, Coodetec, Fundação MT, Pioneer, Fundacep, entre outras empresas, a pedido das mesmas. Estas por sua vez, através de retro-cruzamentos ou de cruzamentos com as cultivares originais e com outras, buscam a obtenção de novas cultivares de soja, mais produtivas, com melhores características e RR. Assim, quando o consumidor adquirir semente transgênica RR legal e certificada, há necessidade de se considerar dois aspectos: a) a semente como royaltie ao obtentor; e outro, b) a semente e a taxa de incentivo tecnológico (Royalties ao $\mathrm{RR})$.

Deve-se ressaltar que para a safra 2003/2004 foi firmado acordo sobre o pagamento de royalties pelo uso da tecnologia Roundup Ready à empresa Monsanto, no valor de R\$ 0,60 para cada saca de $60 \mathrm{Kg}$, sendo que esse fator foi adicionado aos custos de produção da soja transgênica na safra 2003/2004.

\subsection{Custos de produção}

O cálculo do custo de uma determinada cultura estabelece custos de produção associados aos diversos padrões tecnológicos e preços de fatores em uso nas diferentes situações ambientais. Neste custo deve constar como informação básica a combinação de insumos, de serviços e de máquinas e implementos utilizados ao longo do processo produtivo. Esta combinação é conhecida como "pacote tecnológico" e indica a quantidade de cada item em particular, por unidade de área (hectare), que resulta num determinado nível de produtividade, (CONAB,2002). Essas quantidades 
mencionadas, referidas a unidade de área (hectare) são denominadas de coeficientes técnicos de produção, podendo ser expressas em tonelada, quilograma ou litro (corretivos, fertilizantes, sementes e defensivos), em horas (máquinas e equipamentos) e em dia de trabalho (humano ou animal). Dadas as peculiaridades da atividade agrícola, os referidos coeficientes são influenciados diretamente pela diversidade de condições ambientais de clima, de fertilidade, de tipos e topografia do solo.

\subsubsection{Mensuração dos componentes de custos}

Do ponto de vista da mensuração dos custos de oportunidade social, os critérios adotados para sua determinação são os seguintes:

a) CUSTOS EXPLÍCITOS - Cujos valores podem ser mensurados de forma direta, são determinados de acordo com os preços praticados pelo mercado, admitindo-se que os mesmos representam seus verdadeiros custos de oportunidade social. Situam-se nesta categoria os componentes de custo que são desembolsados pelo agricultor no decorrer de sua atividade produtiva, tais como insumos (sementes, fertilizantes e agrotóxicos), mão-de-obra temporária, serviços de máquinas e animais, juros, impostos e outros. (CONAB, 2002)

b) CUSTOS IMPLÍCITOS - Não são diretamente desembolsados no processo de produção, visto que correspondem a remuneração de fatores que já são de propriedade da fazenda, mas não podem deixar de ser considerados, uma vez que se constituem, de fato, em dispêndios. Sua mensuração se dá de maneira indireta, através da imputação de valores que deverão representar o custo de oportunidade de seu uso. Nesta categoria enquadram-se os gastos com depreciação de benfeitorias, instalações, máquinas e implementos agrícolas e remuneração do capital fixo e da terra. (CONAB,2002).

Observa-se ainda que, em termos contábeis, os custos variáveis são separados em despesas de custeio da lavoura, despesas de pós-colheita e despesa financeira, esta última incidente sobre o capital de giro utilizado. Da mesma forma, os custos fixos são diferenciados em depreciação do capital fixo e demais custos fixos envolvidos na produção e remuneração dos fatores terra e capital fixo.

Em termos econômicos, os componentes do custo são agrupados, de acordo com sua função no processo produtivo, nas categorias de custos variáveis, custos fixos, custo operacional e custo total.

Nos custos variáveis são agrupados todos os componentes que participam do processo, na medida que a atividade produtiva se desenvolve, ou seja, aqueles que somente ocorrem ou incidem 
se houver produção. Enquadram-se aqui os itens de custeio, as despesas de pós-colheita e as despesas financeiras. No planejamento de política econômica adotada para cada produto, os custos variáveis desempenham papel crucial na definição do limite inferior do intervalo dentro do qual o preço mínimo deve variar, constituindo-se, no curto prazo, numa condição necessária para que o produtor continue na atividade.

Nos custos fixos, enquadram-se os elementos de despesas que são suportados pelo produtor, independentemente do volume de produção, tais como depreciação, seguros, manutenção periódica de máquinas e outros.

O custo operacional é composto de todos os itens de custos variáveis (despesas diretas) e a parcela dos custos fixos diretamente associada à implementação da lavoura. Difere do custo total apenas por não contemplar a renda dos fatores fixos, consideradas aqui como remuneração esperada sobre o capital fixo e sobre a terra. É um conceito de maior aplicação em estudos e análises que vislumbrem horizontes de médio prazo.

O custo total de produção compreende o somatório do custo operacional mais a remuneração atribuída aos fatores de produção. Numa perspectiva de longo prazo todos esses itens devem ser considerados na formulação de políticas para o setor.

\subsubsection{Descrição dos itens que compõem o custo de produção}

Considerando os critérios de organização apresentados acima, os elementos do custo de produção agrícola são reunidos segundo o plano de contas a seguir:

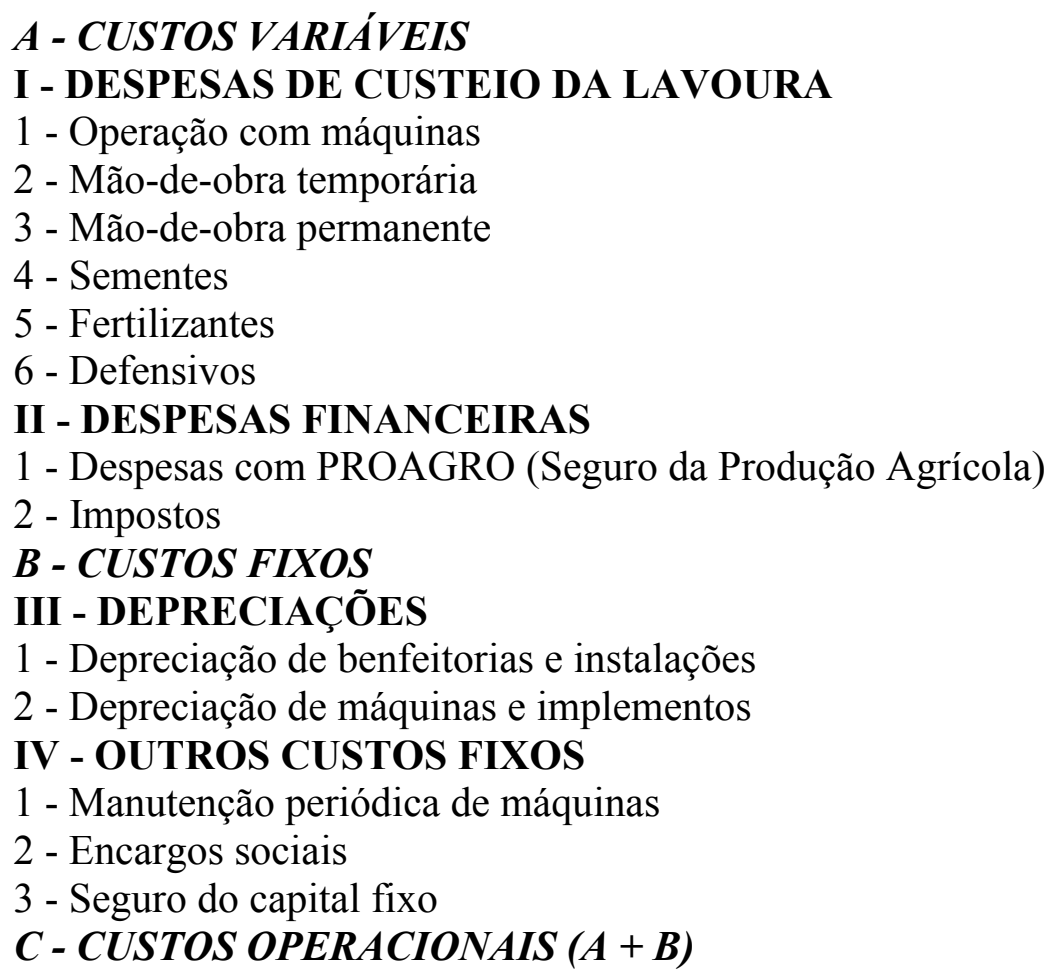




\section{V - RENDA DE FATORES}

1 - Remuneração esperada sobre capital fixo

2 - Terra

D - CUSTO TOTAL $(C+V)$

Utilizando-se de metodologia similar à utilizada pela CONAB (2002), os elementos mais representativos do custo podem ser assim compreendidos:

\section{A) Operação com máquinas}

O valor que aparece nesta conta resulta do somatório das despesas com operações mecanizadas, específicas da cultura da soja no sistema de plantio direto, sendo considerado as seguintes operações: Aplicação de herbicidas para dessecação, plantio e adubação de manutenção, tratos culturais (aplicação de defensivos e aplicação mecânica de adubo de cobertura). Este trabalho efetuou o levantamento dos custos de produção somente até a fase da colheita da soja, desconsiderando os custos pós-colheita (Transporte externo e beneficiamento dos grãos) $\mathrm{O}$ dispêndio em cada operação é obtido mediante a multiplicação do respectivo coeficiente técnico pelo custo horário de máquina.

O custo horário de máquina é calculado a partir de notas fiscais apresentadas pelos produtores comprovando os gastos com consumo de óleo combustível, lubrificantes, filtros, pequenos reparos e salário do operador.

\section{B) Mão-de-obra}

De acordo com a metodologia de cálculo, foram imputados como mão-de-obra somente em algumas propriedades que utilizavam mão-de-obra auxiliar (diaristas), na época de plantio e colheita, considerando que na maioria das propriedades ocorre a mão de obra familiar.

\section{C) Insumos}

Refere-se às despesas de aquisição de fertilizantes, defensivos agrícolas e sementes.

\section{D) Depreciações}

Consideram-se aqui as despesas referentes à depreciação dos bens materiais (imóveis, máquinas e equipamentos) utilizados pelo agricultor. 
O método utilizado para o cálculo das depreciações foi o linear que considera a depreciação como uma função linear da idade do bem, variando uniformemente ao longo da vida útil.

Depreciação de benfeitorias: os valores da depreciação com edificações (casa e galpão), são obtidos conforme fórmula abaixo:

$$
\square V N-V R \square / V U a \square x T \text { Ocup }\} / A R E A
$$

Onde:

$V N=$ valor do bem novo.

$V R=$ valor residual do bem.

$V U a=$ vida útil do bem definida em anos.

T.Ocup = taxa de ocupação do bem, definida como sendo o percentual de utilização deste bem em uma determinada lavoura, obtido a partir da média de utilização dos tratores nesta lavoura.

$A ́ R E A=$ área cultivada da lavoura.

Depreciação de máquinas e equipamentos: para estes bens o cálculo da depreciação se dá através da seguinte fórmula:

Onde:

$V N=$ Valor do bem novo.

$V R=$ Valor residual do bem.

$V U h=$ Vida útil do bem definida em horas.

$H s \mathrm{Tr}=$ total de horas trabalhadas por hectare pelo bem, em uma safra, para realizar todas as tarefas de preparo do solo à colheita em uma dada lavoura.

\section{E) Juros sobre capital de giro}

É a remuneração atribuída ao montante de capital fixo (benfeitorias, instalações, máquinas e equipamentos) empregado na produção. Considera-se, para tanto, qual seria a remuneração percebida pelo capital empatado em ativos fixos na produção, em seu melhor uso alternativo. No presente caso, utiliza-se a taxa média real de 4,37\% ao semestre, (remuneração paga às aplicações em caderneta de poupança), como representativa do custo de oportunidade do capital fixo empregado no processo de produção agrícola. 


\section{Apresentação dos resultados}

\subsection{Composição do custo de produção}

Este estudo objetivou levantar os custos primários da produção da soja não transgênica em dez propriedades rurais no município de Toledo, na safra 2003/2004, através de dados reais, e estabelecer um comparativo com os custos da produção da soja transgênica.

Para o trabalho, inicialmente foram avaliados os custos da produção da soja não transgênica, a partir de gastos comprovados por meio de notas fiscais, onde verificou-se que os custos relativos a insumos variaram entre $47,14 \%$ a $75 \%$ do total do custo, chegando-se a valores entre R\$ 506,23 e R\$ 1.105,30 por hectare, sendo que o item que mais influenciou o custo foi o fertilizante, que absorveu em média $31 \%$ dos investimentos relativos a insumos, tendo um custo médio entre R\$125,60 e R \$313,94 por hectare. Já o segundo item de maior influência no custo de produção da soja não transgênica foi a aplicação do herbicida pós-emergente com 24,76\%, ocorrendo uma variação entre $\mathrm{R} \$ 142,09$ e $\mathrm{R}$ \$284,91 por hectare. Os custos operacionais variaram em torno de $22,22 \%$ a $52,56 \%$ do total do custo de produção, deste valor $15,6 \%$ é determinado pela operação da colheita, gerando o maior custo apontado dentro do fator de serviços. (Tabela 1)

Na seqüência, através de um levantamento realizado no estado do Rio Grande do Sul, região esta que apresenta uma grande parcela de suas áreas cultivadas com OGMs, verificou-se que o custo do Glifosato, ou seja, do herbicida pós-emergente após dois anos, com a utilização de soja transgênica é em torno de R $\$ 25,00$ por hectare, valor este apontado, considerando a utilização de 2 litros por hectare, sendo que cada litro tem um custo em média de $\mathrm{R} \$ 12,50$.

Como na região de abordagem deste levantamento não era permitido o plantio de OGMs, os cálculos foram realizados por meio de uma simulação do custo de produção da soja transgênica substituindo o valor do herbicida pós-emergente dos custos demonstrados na tabela 1, pelo valor indicado em condições iguais no Rio Grande do Sul, que é de R\$ 25,00 por hectare.

Nos resultados encontrados pode ser visualizado que o custo de produção da soja transgênica é nitidamente inferior ao da soja não transgênica, devido à grande redução do custo do herbicida pós-emergente, verificando que com a utilização do herbicida Glifosato ocorre uma redução no número de aplicações, ocorrendo, simultaneamente uma redução nos valores gastos pelos produtores conforme Tabela 2.

Uma breve análise na tabela comparativa dos custos de produção da soja transgênica revela, através de gastos comprovados por meio de notas fiscais, que o custo relativo a insumos variou entre $40,2 \%$ a $73,5 \%$. Isto ocorreu porque os valores relativos ao uso de herbicidas caíram drasticamente, variando entre $2,87 \%$ a $6,94 \%$ do custo relativo aos insumos. 
TABELA 1 - Custos de produção da soja não transgênica nas dez propriedades abordadas no município de Toledo, safra 2003/2004 em valores reais.

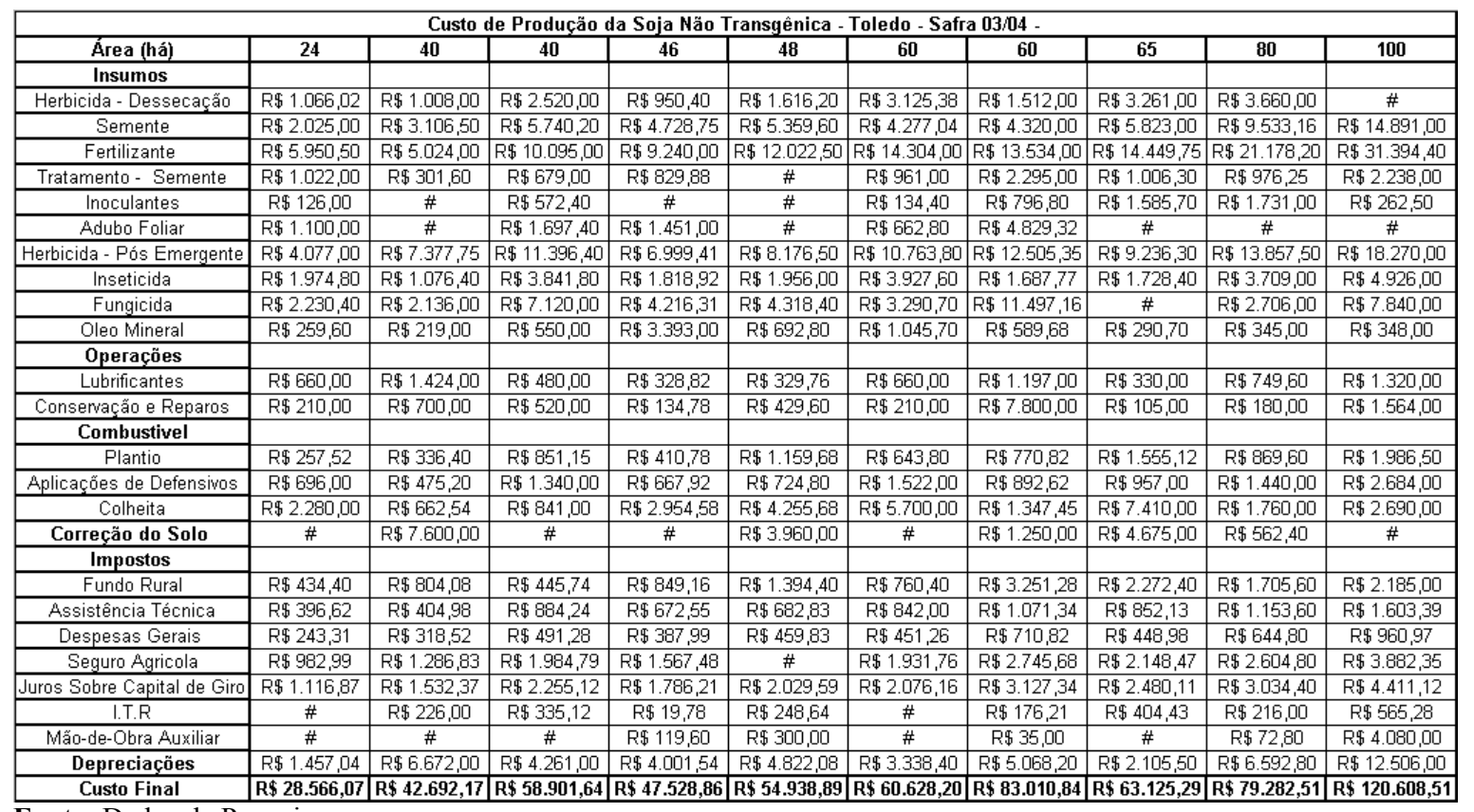

Fonte: Dados da Pesquisa

TABELA 2 - Simulação do custo de produção da soja transgênica, ocorrendo somente redução de aplicações do herbicida pós-emergente, devido a utilização do GLIFOSATO considerando um custo de R\$25,00/ha.

\begin{tabular}{|c|c|c|c|c|c|c|c|c|c|c|}
\hline \multicolumn{11}{|c|}{ Custo de Produção da Soja Transgênica - Roundup Ready - Toledo - Safra 03/04 } \\
\hline Herbicida - Dessecação & $\mathrm{R} \$ 1.066,02$ & $\mathrm{R} \$ 1.008,00$ & $\mathrm{R} \$ 2.520,00$ & $\mathrm{R} \$ 950,40$ & $\mathrm{R} \$ 1.615,80$ & $\mathrm{R} \$ 3.125,38$ & $\mathrm{R} \$ 1.512,00$ & $\mathrm{R} \$ 3.261,00$ & $\mathrm{R} \$ 3.660,00$ & \# \\
\hline Semente & $\mathrm{R} \$ 2.520,00$ & $\mathrm{R} \$ 3.640,00$ & $\mathrm{R} \$ 6.720,00$ & $\mathrm{R} \$ 5.250,00$ & $\mathrm{R} \$ 9.856,00$ & $\mathrm{R} \$ 5.936,00$ & $\mathrm{R} \$ 5.600,00$ & $\mathrm{R} \$ 10.248,00$ & $\mathrm{R} \$ 10.192,00$ & $\mathrm{R} \$ 14.504,00$ \\
\hline Tratamento - Semente & $\mathrm{R} \$ 1.022,00$ & $\mathrm{R} \$ 301,60$ & $\mathrm{R} \$ 679,00$ & $\mathrm{R} \$ 829,88$ & \# & $\mathrm{R} \$ 961,00$ & $\mathrm{R} \$ 2.295,00$ & $\mathrm{R} \$ 1.006,30$ & $\mathrm{R} \$ 976,85$ & $\mathrm{R} \$ 2.238,00$ \\
\hline Inoculantes & $\mathrm{R} \$ 126,00$ & $\#$ & $\mathrm{R} \$ 572,40$ & $\#$ & \# & $\mathrm{R} \$ 134,40$ & $\mathrm{R} \$ 796,80$ & $\mathrm{R} \$ 1.585,70$ & $\mathrm{R} \$ 1.731,40$ & $\mathrm{R} \$ 262,50$ \\
\hline Adubo Foliar & $\mathrm{R} \$ 1.100,40$ & \# & $\mathrm{R} \$ 1.697,40$ & $\mathrm{R} \$ 1.451,00$ & \# & $\mathrm{R} \$ 662,80$ & $\mathrm{R} \$ 4.829,32$ & \# & $\#$ & $\#$ \\
\hline Oleo Mineral & $\mathrm{R} \$ 259,60$ & $\mathrm{R} \$ 219,00$ & $\mathrm{R} \$ 550,00$ & $\mathrm{R} \$ 3.393,00$ & $\mathrm{R} \$ 691,80$ & $\mathrm{R} \$ 1.045,70$ & $\mathrm{R} \$ 589,68$ & $\mathrm{R} \$ 290,70$ & $\mathrm{R} \$ 345,00$ & $\mathrm{R} \$ 348,00$ \\
\hline \multicolumn{11}{|l|}{ Operações } \\
\hline Lubrificantes & $\mathrm{R} \$ 660,00$ & $R \$ 1.424,00$ & $\mathrm{R} \$ 480,00$ & $\mathrm{R} \$ 328,82$ & $\mathrm{R} \$ 330,00$ & $\mathrm{R} \$ 660,00$ & $\mathrm{R} \$ 1.197,00$ & $\mathrm{R} \$ 330,00$ & $\mathrm{R} \$ 749,60$ & $R \$ 1.320,00$ \\
\hline Conservaçắo e Reparos & $\mathrm{R} \$ 210,00$ & $\mathrm{R} \$ 700,00$ & $\mathrm{R} \$ 520,00$ & $\mathrm{R} \$ 134,78$ & $\mathrm{R} \$ 430,00$ & $\mathrm{R} \$ 210,00$ & $\mathrm{R} \$ 7.800,00$ & $\mathrm{R} \$ 105,00$ & $\mathrm{R} \$ 180,00$ & $\mathrm{R} \$ 1.564,00$ \\
\hline \multicolumn{11}{|l|}{$\begin{array}{l}\text { Combustivel } \\
\end{array}$} \\
\hline Plantio & $\mathrm{R} \$ 257,52$ & $\mathrm{R} \$ 336,40$ & $\mathrm{R} \$ 851,15$ & $\mathrm{R} \$ 410,78$ & $\mathrm{R} \$ 1.160,00$ & $\mathrm{R} \$ 643,80$ & $\mathrm{R} \$ 770,82$ & $\mathrm{R} \$ 1.555,12$ & $\mathrm{R} \$ 869,60$ & $\mathrm{R} \$ 1.986,50$ \\
\hline Assistência Técnica & $\mathrm{R} \$ 337,00$ & $\mathrm{R} \$ 288,10$ & $\mathrm{R} \$ 695,91$ & $\mathrm{R} \$ 566,25$ & $\mathrm{R} \$ 633,25$ & $\mathrm{R} \$ 697,75$ & $\mathrm{R} \$ 876,83$ & $\mathrm{R} \$ 683,89$ & $\mathrm{R} \$ 929,96$ & $R \$ 1.280,25$ \\
\hline Despesas Gerais & $\mathrm{R} \$ 207,74$ & $\mathrm{R} \$ 256,53$ & $\mathrm{R} \$ 387,57$ & $\mathrm{R} \$ 329,30$ & $\mathrm{R} \$ 430,92$ & $\mathrm{R} \$ 434,51$ & $\mathrm{R} \$ 603,76$ & $\mathrm{R} \$ 494,32$ & $\mathrm{R} \$ 522,08$ & $\mathrm{R} \$ 779,34$ \\
\hline Seguro Agricola & $\mathrm{R} \$ 839,30$ & $\mathrm{R} \$ 1.036,40$ & $\mathrm{R} \$ 1.565,80$ & $\mathrm{R} \$ 1.330,40$ & $\#$ & $\mathrm{R} \$ 1.755,44$ & $\mathrm{R} \$ 2.309,14$ & $\mathrm{R} \$ 2.483,08$ & $\mathrm{R} \$ 2.109,22$ & $\mathrm{R} \$ 1.850,00$ \\
\hline I.T.R & $\#$ & $\mathrm{R} \$ 226,00$ & $\mathrm{R} \$ 335,12$ & $\mathrm{R} \$ 20,00$ & $\mathrm{R} \$ 295,36$ & $\#$ & $\mathrm{R} \$ 176,21$ & $\mathrm{R} \$ 404,43$ & $\mathrm{R} \$ 216,36$ & $\mathrm{R} \$ 565,28$ \\
\hline Mão-de-Obra Auxiliar & \# & $\#$ & $\#$ & $\mathrm{R} \$ 120,00$ & $\mathrm{R} \$ 300,00$ & $\#$ & $\mathrm{R} \$ 35,00$ & $\#$ & $\mathrm{R} \$ 72,80$ & $\mathrm{R} \$ 4.080,00$ \\
\hline Juros Sobre Capital de Giro & $\mathrm{R} \$ 953,61$ & $\mathrm{R} \$ 1.177,56$ & $\mathrm{R} \$ 1.779,07$ & $\mathrm{R} \$ 1.516,84$ & $\mathrm{R} \$ 1.901,99$ & $\mathrm{R} \$ 1.994,53$ & $\mathrm{R} \$ 2.631,34$ & $R \$ 2.269,09$ & $\mathrm{R} \$ 2.396,50$ & $\mathrm{R} \$ 3.439,79$ \\
\hline $\begin{array}{l}\text { Depreciaçőes } \\
\end{array}$ & $\mathrm{R} \$ 848,64$ & $R \$ 6.125,20$ & $\mathrm{R} \$ 4.051,00$ & $\mathrm{R} \$ 1.963,00$ & $\mathrm{R} \$ 3.582,04$ & $\mathrm{R} \$ 2.121,60$ & $\mathrm{R} \$ 4.715,40$ & $\mathrm{R} \$ 1.619,50$ & $\mathrm{R} \$ 4.537,20$ & $\mathrm{R} \$ 8.986,00$ \\
\hline Royalties & $\mathrm{R} \$ 298,20$ & $\mathrm{R} \$ 552,00$ & $\mathrm{R} \$ 306,00$ & $\mathrm{R} \$ 583,20$ & $\mathrm{R} \$ 960,00$ & $\mathrm{R} \$ 522,00$ & $\mathrm{R} \$ 2.232,00$ & $\mathrm{R} \$ 1.625,00$ & $\mathrm{R} \$ 1.171,20$ & $\mathrm{R} \$ 1.500,00$ \\
\hline Custo Final & $R \$ 24.356,73$ & $R \$ 35.831,41$ & $R \$ 47.627,96$ & $R \$ 39.642,62$ & $R \$ 51.658,06$ & $R \$ 51.040,11$ & $R \$ 73.632,56$ & $R \$ 60.600,68$ & $R \$ 64.867,47$ & $R \$ 97.240,06$ \\
\hline
\end{tabular}

Fonte: Dados da Pesquisa.

Já na tabela 3 tem-se o valor do retorno em potencial para o município de Toledo - PR, com a implantação de soja transgênica apenas na economia do herbicida pós-emergente. Nele verifica-se que há uma economia máxima de $\mathrm{R} \$ 281,84$ (duzentos e oitenta e um reais e oitenta e quatro centavos) e uma mínima de $\mathrm{R} \$ 39,15$ (trinta e nove reais e quinze centavos). 
Considerando-se que a região de Toledo-PR possui 68800 ha cultiváveis para a soja isto traria uma economia variando entre R $\$$ 2.693.520,00 (Dois milhões, seiscentos e noventa e três mil e quinhentos e vinte reais) a $\mathrm{R} \$ 19.390 .592,00$ (Dezenove milhões, trezentos e noventa mil e quinhentos e noventa e dois reais) para a região.

TABELA 3 - Valor do retorno em potencial para o município de Toledo - PR, com a implantação de soja transgênica no município.

\begin{tabular}{|c|c|c|c|}
\hline & Economia R\$/ha & $\begin{array}{c}\text { Área de Soja } \\
\text { Toledo (ha) }\end{array}$ & $\begin{array}{c}\text { Retorno em potencial para } \\
\text { Toledo (R\$) }\end{array}$ \\
\hline Máximo & 281,84 & 68800 & $19.390 .592,00$ \\
\hline Média & 163,98 & 68800 & $11.281 .824,00$ \\
\hline Mínimo & 39,15 & 68000 & $2.693 .520,00$ \\
\hline
\end{tabular}

Fonte: Dados da Pesquisa.

\section{Conclusões}

O objetivo deste trabalho foi o de apresentar um comparativo de custos de produção entre a cultura da Soja Convencional e da Soja Transgênica no Município de Toledo, estado do Paraná, na Safra de 2003/2004, analisando os aspectos que envolvem a produção da soja, com seqüente avaliação sobre a economia gerada através da diminuição de aplicações e quantidade de herbicidas na fase pós emergente na soja Rondup Ready.

O resultado positivo estimado, demonstrado no comparativo entre a soja convencional e transgênica, pode ser considerado como um ponto de partida para novas pesquisas e levantamentos sobre o tema. Os números atuais são limitados para uma avaliação mais definitiva pois, por ser a transgenia uma tecnologia bastante recente, são poucos os estudos existentes, e muito ainda a ser realizado.

Mudanças nos padrões do clima global e alterações no uso da terra ampliarão os problemas regionais de produção. Aumentar a produção, entretanto, é somente uma parte da equação. O aumento da renda e efetiva distribuição dos estoques de alimentos, especialmente em áreas de grande desigualdade social, são tão ou mais importantes. Alguns desses avanços virão de tecnologias que nada tem a ver com a transformação de plantas, porém outras virão das vantagens oferecidas pelas tecnologias que criam organismos geneticamente modificados, os chamados transgênicos.

A biotecnologia surge, potencialmente, como um importante fator que permite ganhos de produtividade e aumento de oferta de alimentos, ao mesmo tempo em que pode reduzir o ritmo de exploração de novas áreas agricultáveis, gerando com isto externalidades positivas para o meio ambiente e a sociedade como um todo. 


\begin{abstract}
To face with efficiency the great competitiveness that characterizes the soybean complex, its necessary to use technologies since the primary production. Thus, this study aims to compare the production cost between the non transgenic soybean and the transgenic soybean (Roundup Ready variety), in Toledo city, state of Paraná, in the haverst of 2003/2004.
\end{abstract}

Key words: Soybean, Transgenics, Production costs

\title{
Referências
}

ANVISA - Agência Nacional de Vigilância Sanitária. Instrução Normativa Conjunta no 02/2002. Disponível em http// www.anvisa.gov.br. Acesso em 15 out. 2004.

ANVISA - Agência Nacional de Vigilância Sanitária. Instrução Normativa no 24/2002 do Ibama e a Resolução $\mathbf{n}^{\circ}$ 57/2002 da Anvisa. Disponível em http// www.anvisa.gov.br. Acesso em 15 out. 2004.

ASSOCIAÇÃO NACIONAL DE BIOSSEGURANÇA. Disponível em: http://www.anbio.org.br. Acesso em: 04 jan. 2004.

BARNES, David. Alimentos transgênicos no mundo. Disponível em: www.fortunecity.com/campus/biology/752/. Acesso em: 23 out. 2004.

BINSFELD, P. C. Análise diagnóstica de um produto transgênico. Biotecnologia, Ciência e Desenvolvimento, Brasília, v. 2, n. 12, p. 16-19, 2000.

CAVALLI, Suzi Barletto. Food safety: the approach to transgenic foods. Rev. Nut., v.14, supl., p.41-46, 2001.

COMPANHIA NACIONAL DE ABASTECIMENTO.Custos de produção agrícola: 2002. Disponível em: http://www.conab.com.br. Acesso em: 15 out. 2004.

COMPANHIA NACIONAL DE ABASTECIMENTO. Safras 2003/2004. Disponível em: http://www.conab.com.br. Acesso em: 15 out. 2004.

CONAMA - Conselho Nacional do Meio Ambiente. Resolução no 305/2002. Disponível em : http//www.mma.gov.br/port/conama/res/res02/res30502.html. Acesso em 15 set. 2004.

GAZZONI, Décio. Agregando valor ao agronegócio. Disponível em: http://www.cib.org.br. Acesso em: 10 nov. 2004.

LEITE, M. Os alimentos transgênicos. São Paulo: Publifolha,2000.

LOUREIRO, A. P. Informativo Fundação Pró-Sementes \& Apassul. Disponível em: http://www.apasssul.com.br. Acesso em: 16 out. 2004.

MELGAREJO, L. A safra transgênica de 2002/2003. Porto Alegre: EMATER, 2003.

MMA - Ministério do Meio Ambiente. Decreto-Lei $n^{0}$ 6.938/81 e no Anexo da Lei $\mathbf{n}^{0}$ 10.165/2000. Disponível em http//www.mma.gov.br/port. Acesso em 13 out. 2004.

MMA - Ministério do Meio Ambiente. Decreto-Lei $n^{0}$ 7.802/89 e o Decreto $\mathbf{n}^{\mathbf{0}}$ 4.074/2002. Disponível em http//www.mma.gov.br/port. Acesso em 13 out. 2004.

MMA - Ministério do Meio Ambiente. Decreto-Lei no 8.974/95 (Lei de Biossegurança), alterada pela Medida Provisória $n^{0}$ 2.191-9/2001, e seu decreto regulamentador (Decreto $\mathbf{n}^{\mathbf{0}} \mathbf{1 . 7 5 2 / 9 5}$ ). Comissão Técnica Nacional de Biossegurança (CTNBio). Disponível em http//www.mma.gov.br/port. Acesso em 11 out. 2004. 
NODARI, R. O., GUERRA, M. P. Plantas transgênicas e seus produtos: impactos, riscos e segurança alimentar. In: SIMPÓSIO SUL-BRASILEIRO DE ALIMENTAÇÃO, [S.1.], 2000. Anais... [S.1.], 2000.

ORGANIZAÇÕES DAS COPERATIVAS DO ESTADO DO PARANÁ. Banco de dados. Disponível em: http://www.ocepar.org.br/ocepar/index.html. Acesso em: 26 set. 2004.

ROESSING, A. C. Pesquisador da Empresa Brasileira de Pesquisa Agropecuária (EMBRAPA). Disponível em: http://www.cnpso.embrapa.com.br. Acesso em: 25 set. 2004.

RUEDELL, J. Cultura da soja: a verdade sobre a transgenia. Passo Fundo: FUNDACEP, 2003. 